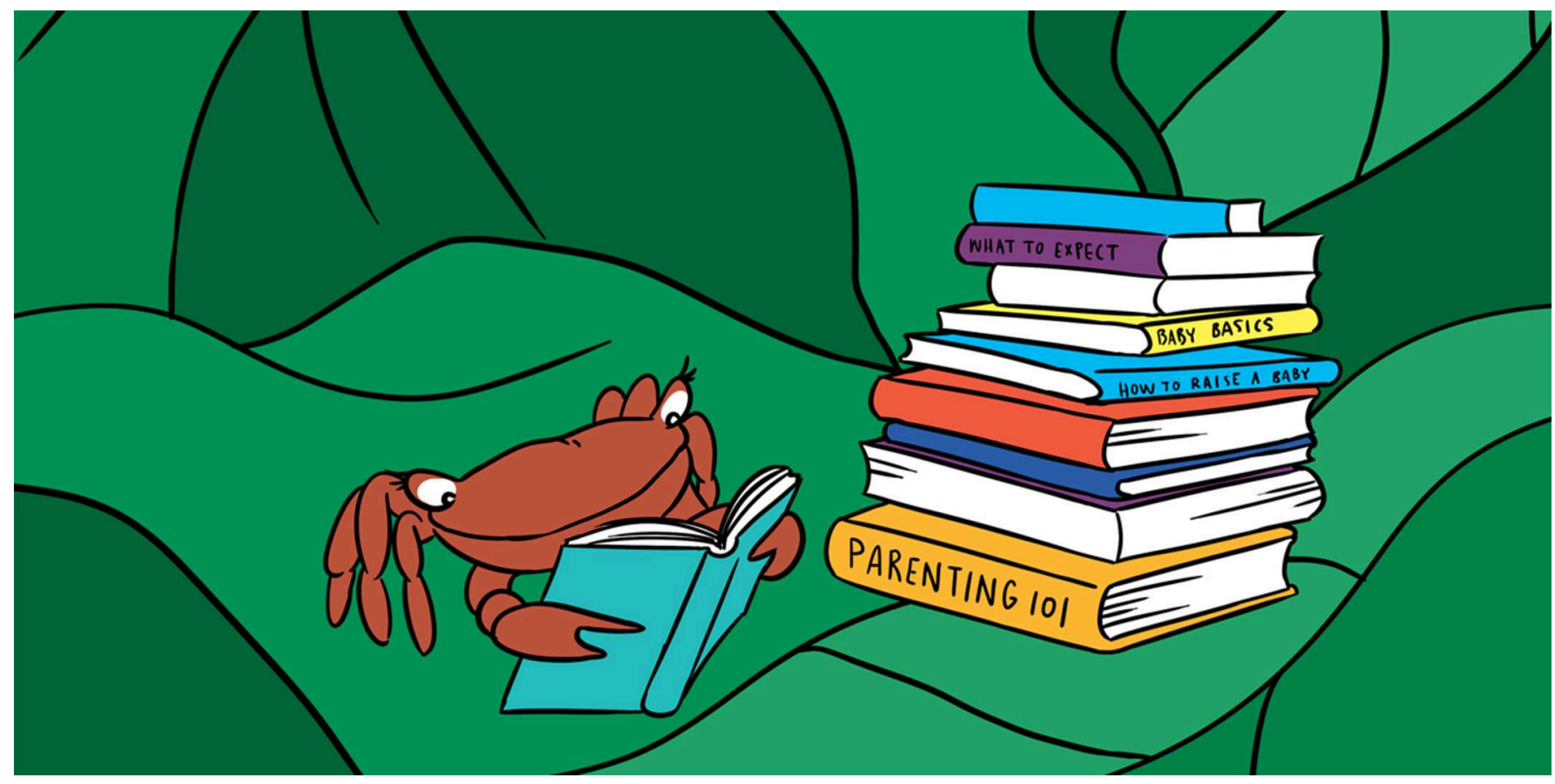

\title{
WHO CARES? PARENTING IN INVERTEBRATE ANIMALS
}

\section{Angela Chuang * and Orlando Schwery}

Department of Ecology and Evolutionary Biology, The University of Tennessee, Knoxville, TN, United States

YOUNG REVIEWER:

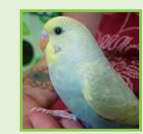

EREN

AGE: 8
Many of us find it hard to relate to spiders or other types of invertebrates, including insects, snails, clams, jellyfish, and squid. With over a million species, invertebrates (which are animals that do not have spines) make up most of Earth's animals, and their behaviors are quite diverse. It might be surprising to hear that some invertebrates take care of their offspring by feeding, protecting, and raising them. The type of care given to offspring, including which parent is involved, generally depends on the environment these animals live in. Invertebrates often have parenting strategies that allow them to produce the greatest number of surviving offspring over the course of their lives. Since their time and energy is limited, some invertebrate species prioritize making lots of offspring over providing care, while others do the opposite. We also describe special examples of parental care, to illustrate the fascinating sacrifices some invertebrate parents make. These might not seem so different from what our own parents are willing to do for us! 


\section{INVERTEBRATE}

An animal without a spine, such as an insect, spider, worm, slug, crab, clam, squid, etc.

\section{VERTEBRATE}

An animal with a spine, such as a bird, mammal, fish, amphibian, or reptile.

\section{BROOD}

A group of young animals, often hatched at the same time.

\section{INTRODUCTION}

Most of us grow up relying a lot on our parents. Our moms and dads feed us, clothe us, teach us, and keep us safe. If you think about what parenting looks like in animals, you might think about mama bears, known for their fierce protectiveness of their cubs. Or you might think of birds who take turns feeding their helpless chicks, or kangaroos carrying joeys in their pouches.

But what about other animals, such as invertebrates? Invertebrates are animals without spines, including insects, snails, worms, crabs, and squids. Even though we know a lot less about the lives of invertebrates compared to vertebrates like birds, mammals, fish, amphibians, and reptiles, invertebrates actually make up a stunning $95 \%$ of all the different animals on Earth! That means a lot of creatures in this world look and behave very differently from humans. Learning about invertebrates can teach us about different ways of living.

In this article, we will talk about (1) why some invertebrates perform parental care, (2) some examples of how they do this, and (3) why some species have single moms, single dads, or both parents caring for their offspring.

\section{WHY DO SOME INVERTEBRATES CARE FOR THEIR OFFSPRING, WHILE OTHERS DO NOT?}

There are a lot of different and complex ways that invertebrates care for their young, which makes it hard to say how this behavior evolved in the first place. However, there are a few ideas about factors that influence parental care in different species. One important factor is the environment the invertebrates raise their young in. First, parental care is really important for animals that live in harsh environments, like in a desert, where eggs or young cannot easily survive without the help of their parents [1]. Second, when food is scarce and only around for a short time, there can be lots of competition for it. In this case, young animals need their parents' help to get enough food. Last, parents may need to guard their offspring from predators that want to eat them.

Another important factor influencing parental car is the number of offspring that survive when parents are around vs. when parents are not. The number of surviving young influences how many copies of the parents' genes are passed on to the next generation. In fact, the total number of surviving offspring over a parent's life is much more important than the success of a single batch of offspring (called a brood) [1, 2]. Depending on the circumstances, parents might benefit the most from either staying and caring for their young, or from leaving and letting their young fend for themselves [2]. For instance, if parents have only one brood of offspring in their lifetimes, it makes the most 


\section{TROPHIC EGGS}

Unfertilized eggs laid by a mother for her offspring to eat.

\section{CANNIBALISM}

The act of eating one's own species.

\section{REGURGITATION}

The act of bringing swallowed food up from the stomach to the mouth again, like vomiting. sense for them to stay and help as many young as possible survive to adulthood. Parents are also more likely to stay and care if they have already spent a lot of time and energy on their offspring, such as guarding their eggs for several weeks, or if the brood is very large. Otherwise, if parents can have several broods of children, it might be a better strategy to use their energy making lots of offspring and letting those offspring try and survive by themselves.

\section{SPECIAL EXAM PLES OF PARENTAL CARE IN INVERTEBRATES}

\section{Feeding offspring}

Some invertebrate parents help feed their offspring. This is possible even in species in which the female dies before her eggs hatch. These females lay what are called trophic eggs, which are an important first meal for the young after they hatch, feeding them until they are old enough to look for food themselves (Figure 1A). Having trophic eggs to eat also reduces cannibalism among hungry siblings!

Although mammals are known for mothers producing milk for their babies, a few invertebrates do something similar. Most insects produce many offspring, but female tsetse flies only produce one larva at a time. This larva stays in the female's uterus, where it feeds on a milk-like liquid [3]. In the jumping spider Toxeus magnus, the mother also produces a nutritious, milk-like liquid that her offspring drink from her body, much like a cow and her calf [4].

As an extreme example of a mother's sacrifice, velvet spiders literally allow their young to eat them alive (Figure 1B)! A velvet spider mother originally feeds her children a nutritious liquid through regurgitation, like some birds do. Eventually, the mother spider allows her kids to eat her alive. The spiderlings do not leave the nest until all traces of their mother have been consumed [1]. While this behavior might seem cruel and unfair to the mother, the spiderlings end up much larger and better able to catch prey and survive because of their mother's sacrifice.

\section{Brooding}

A few invertebrate parents spend a large amount of time physically carrying or protecting their offspring. Male water bugs are model fathers, since they can carry more than 100 eggs on their backs until they hatch (Figure 1C). This behavior keeps the eggs from being gobbled up by predators. Unsurprisingly, brooding so many eggs decreases how well the fathers swim and can make catching prey harder as well [1]. Not only do these water bug fathers carry their unhatched children everywhere, but they spend a lot of time cleaning the eggs with their hind legs. Eggs that stay on their father's backs have a good chance of hatching, while those that fall off never hatch [5]. 
Figure 1

Invertebrates have many ways of helping their offspring to survive. (A) Dog whelks are a type of sea snail that produce many eggs, including trophic eggs. The offspring that hatch from the fertilized eggs eat the trophic eggs as their first meal. Photo by Simon Evans. (B) Mother velvet spiders not only help feed their newly hatched babies by regurgitating food, but eventually allow their spiderlings to eat them alive. This helps the spiderlings grow and makes them more likely to survive and catch their own food in the future. Photo by Dr. Mor Salomon-Botner. (C) Water bug fathers carry their eggs on their back until their young hatch. These fathers make sure their eggs have enough oxygen and do not get infested with fungi or anything that can harm their developing offspring. Photo by

Mark Dumont.
$\mathrm{PH}$

A measurement of how acidic or basic something is.

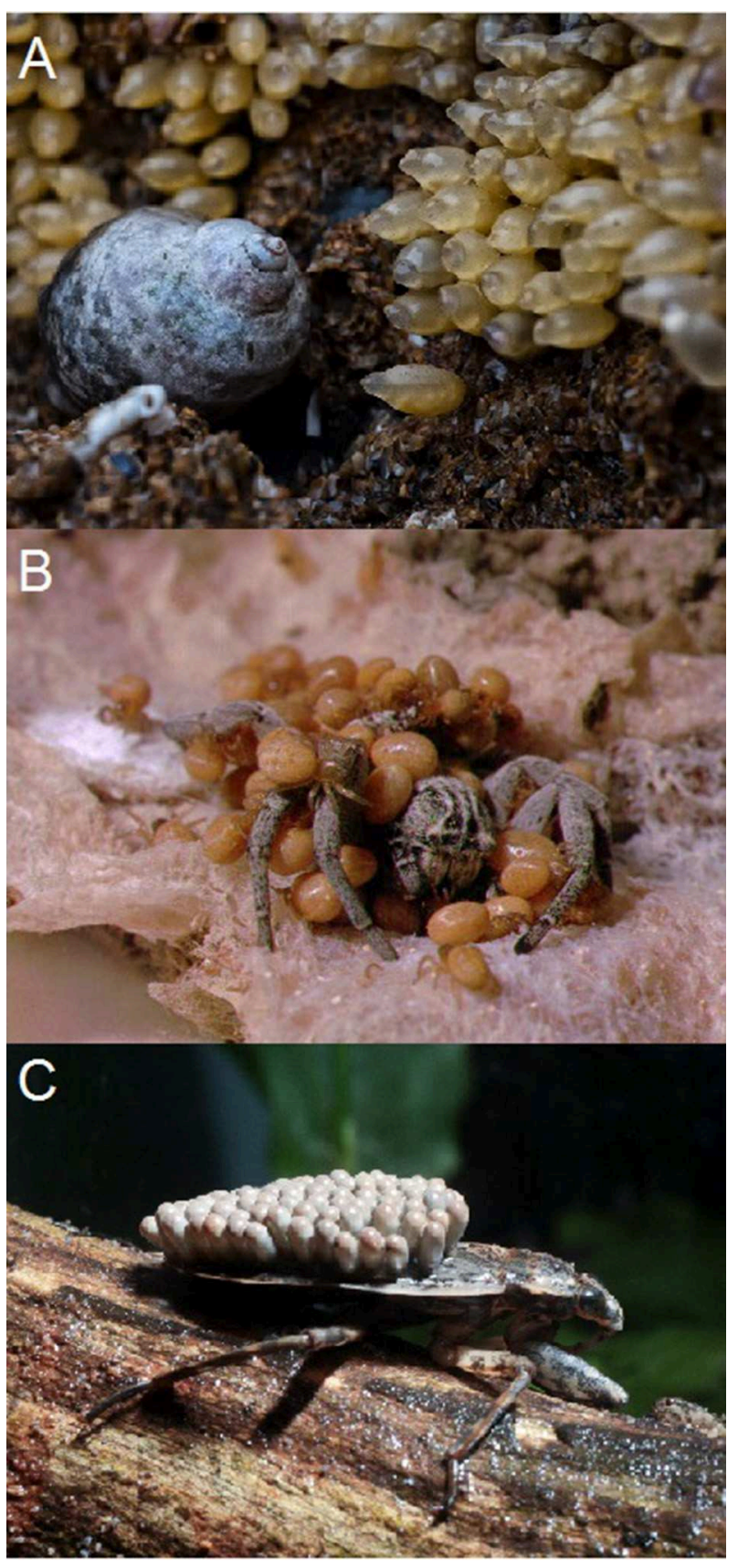

Figure 1

\section{Nurseries}

Other invertebrate parents create nests, burrows, or nurseries for their offspring to grow up in. Jamaican bromeliad crabs, Metopaulias depressus, are unlike many crabs because they live their entire lives on plants called bromeliads, instead of in the ocean or on the beach. Bromeliads are tropical plants whose leaves overlap at the bottom and form a cup that collects water. These pools of water might seem small, but they are ideal nurseries for young crabs of this species to grow up in. Mother crabs make sure these pools have the right balance of oxygen, carbon dioxide, and $\mathbf{p H}$. They do this by removing rotting 
leaves that might make the water too acidic [1]. Mother crabs also increase the calcium content of the water by allowing calcium-rich snail shells to dissolve in it; without this extra calcium, the crab larvae cannot successfully molt and develop to their next stage.

\section{WHO CARES? MOM OR DAD?}

Single motherhood and fatherhood are common among invertebrates, although in some species, both parents stay around to care for offspring. Once again, the type of parenting a species performs depends on how they can produce the greatest numbers of surviving offspring over their lifetimes.

Mothers are most likely to take care of the young alone if they are limited by time or resources. For example, there are not many males available for her to mate multiple times with and produce many different sets of offspring with. Or if it takes a long time to make another batch of eggs, it might make sense for the mother to take care of her young and try to make sure that as many of those offspring survive as possible. Species that only mate once might care more for their offspring, because they only have one chance to make sure some of them survive-some octopodes, for example, guard their eggs for months or even years at a time without leaving to hunt. Because it takes so long for their eggs to hatch, the mothers spend all of their remaining energy guarding a single batch of eggs (Figure 2).

Childcare might fall on the fathers if the mother is busy producing another set of eggs [1, 2]. Since the father is spending his time and energy caring for the offspring, the mother can use her energy in making bigger and healthier eggs, which increases the chance of the eggs surviving. For some animals, a father that guards his offspring is very attractive to other females, because he is actively proving what a good father he is. Other females may choose to mate with him as well and leave their eggs in his territory. This increases the number of offspring he ends up having. Fathers that carry their eggs with them spend a lot of energy caring for offspring, and likely do so only because there are no places to leave them that are safe from predators.

Both parents will partner up to take care of their offspring when lots of work is required and when tasks can be divided between the parents [1]. For example, dung beetle parents work together to claim, build, and bury dung balls into specially made nurseries for their offspring (Figure 2). One parent cannot both build a nest and guard it from intruders, so both parents need to contribute. Both parents are also more likely to raise the young together if the offspring are all full siblings and the female did not mate with several males [1, 2]. Having two parents around is also like an insurance for their young, in case one parent dies before the offspring are independent. 
Figure 2

Some invertebrates provide care to their offspring because without it, the offspring would be unlikely to survive themselves. (A) Octopus eggs can take several weeks, months, or even years to hatch, meaning octopus mothers often defend their eggs from predators. Since the females cannot even leave to hunt during this time, they only have enough energy to create and defend a single batch of eggs. Photo by Phil Garner. (B) Baby dung beetles have an unusual but unsurprising diet-dung! Dung is actually very valuable to some animals, and there is fierce competition to get the freshest, nicest dung out there. The best conditions for these larvae to grow in requires so much work that dung beetle parents need to work together to dig a tunnel and roll a ball of dung into it to create a nursery. Photo by Bernard Dupont.

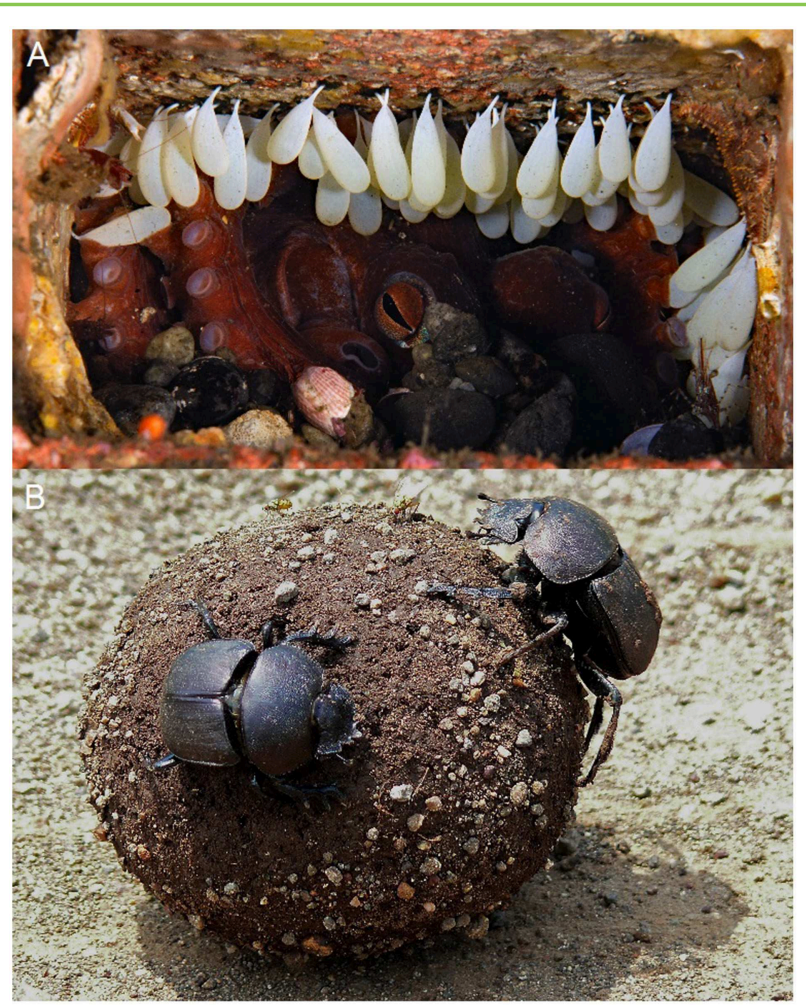

Figure 2

\section{CONCLUSION}

Learning about parental care in invertebrates is important for helping us understand all of the different ways of living that can be successful. Whether invertebrate mothers and fathers care for their offspring all comes down to what will allow the greatest number of young invertebrates to survive. This depends on how harsh and dangerous the environment is, and whether the parents can just leave and have more offspring instead. The next time you think about what makes a good parent, we hope that in addition to mama bears and kangaroos, you also think about spiders, water bugs, and octopodes!

\section{ACKNOWLEDGMENTS}

$\mathrm{AC}$ and OS thank the Department of Ecology and Evolutionary Biology at The University of Tennessee for their support. AC is funded by the NSF Graduate Research Fellowship DGE-201315897. We thank Simon Evans for use of his photo of dog whelk eggs, Dr. Mor Salomon-Botner for use of her photo of Stegodyphus lineatus spiders, and Mark Dumont for his photo of a male water bug. We also thank Phil Garner for his octopus photo and Bernard Dupont for his dung beetle photo. Finally, we thank the Young Reviewer Eren, and his Science Mentor, Dr. Bruno Alves Buzatto, for their helpful comments on this manuscript. 


\section{REFERENCES}

1. Trumbo, S. T. 2012. "Patterns of parental care in invertebrates," in Evolution of Parental Care, eds N. J. Royle, P. T. Smiseth, and M. Kölliker (Oxford: Oxford University Press), 81-100. doi: 10.1093/acprof:oso/9780199692576.003.0005

2. Gross, M. R. 2005. The evolution of parental care. Q. Rev. Biol. 80:37-45. doi: $10.1086 / 431023$

3. Benoit, J. B., Attardo, G. M., Baumann, A. A., Michalkova, V., and Aksoy, S. 2015. Adenotrophic viviparity in tsetse flies: potential for population control and as an insect model for lactation. Annu. Rev. Entomol. (2015) 60:351-71. doi: 10.1146/annurev-ento-010814-020834

4. Chen, Z. Q., Corlett, R. T., Jiao, X. G., Liu, S. J., Charles-Dominique, T., Zhang, S. C., et al. 2018. Prolonged milk provisioning in a jumping spider. Science 362:1052-5. doi: 10.1126/science.aat3692

5. Smith, R. L. 1976. Brooding behavior of a male water bug Belostoma flumineum (Hemiptera: Belostomatidae). J. Kansas Entomol. Soc. 49:333-43.

SUBMITTED: 13 January 2019; ACCEPTED: 16 May 2019;

PUBLISHED ONLINE: 05 June 2019.

EDITED BY: Vishal Shah, West Chester University, United States

CITATION: Chuang A and Schwery O (2019) Who Cares? Parenting in Invertebrate Animals. Front. Young Minds 7:78. doi: 10.3389/frym.2019.00078

CONFLICT OF INTEREST STATEMENT: The authors declare that the research was conducted in the absence of any commercial or financial relationships that could be construed as a potential conflict of interest.

COPYRIGHT @ 2019 Chuang and Schwery. This is an open-access article distributed under the terms of the Creative Commons Attribution License (CC BY). The use, distribution or reproduction in other forums is permitted, provided the original author(s) and the copyright owner(s) are credited and that the original publication in this journal is cited, in accordance with accepted academic practice. No use, distribution or reproduction is permitted which does not comply with these terms.

\section{YOUNG REVIEWER}

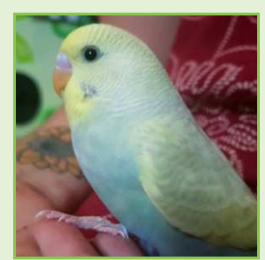

\section{EREN, AGE: 8}

My name is Eren. I am 8 and I like birdwatching. I am in year 2. I like screens. I like going to good birdwatching places. There is always a target bird I am after when I go to birdwatching places. I also like reading Paul Jennings books because they are really weird and cool. 


\section{AUTHORS}

\section{ANGELA CHUANG}

I am currently a Ph.D. candidate at The University of Tennessee, where I study the role of animal behavior in global change, especially biological invasions. At age 20, I finally got over my lifelong fear of spiders, and am now fascinated by them. Spider behaviors are alternately relatable, alien, and taboo to me, and I am excited to learn how these behaviors will prepare them to survive in an increasingly human-dominated world. *angelachuang@atennessee.edu

\section{ORLANDO SCHWERY}

I grew up on a little Swiss farm on the edge of town and have always enjoyed getting lost in nature, observing its many forms and wondering how they came to be. I am currently a Ph.D. student at The University of Tennessee, studying diversification-how and why we have many species of some kinds of organisms, but very few of others. I do this using computer simulations and models, but also by looking at real organisms-plants in the past and dung beetles now. Asides from my research, I enjoy hiking, board games, cooking, reading, and martial arts. 